\title{
Implicações Teóricas do Novo Institucionalismo: Uma Abordagem Habermasiana*
}

\author{
Christina W. Andrews
}

\section{INTRODUÇÃO}

\begin{abstract}
$\mathrm{O}$
Novo Institucionalismo pode ser considerado uma das abordagens teóricas mais influentes na ciência política contemporânea, em especial nos estudos sobre políticas públicas. O pressuposto básico dessa linha teórica é a idéia de que as instituições afetam o comportamento de atores sociais. Apesar dessa orientação teórica geral, o Novo Institucionalismo reúne diferentes argumentos, cada qual assumindo pressupostos específicos. Desde a publicação do trabalho clássico de Hall e Taylor (1996), considera-se que o Novo Institucionalismo possui pelo menos três abordagens: o institucionalismo histórico, o de escolha racional e o sociológico (também referido como o da teoria das organizações). Segundo os autores citados, as influências teóricas do Novo
\end{abstract}

\footnotetext{
* O presente artigo é uma versão adaptada do capítulo nove de minha tese de doutorado, Reificação e Legitimidade: Habermas como Metateoria das Policy Sciences (Faculdade de Filosofia, Letras e Ciências Humanas - FFLCH, Universidade de São Paulo, 2003), que contou com o apoio da Fundação de Amparo à Pesquisa do Estado de São Paulo FAPESP. Agradeço os comentários a uma versão anterior apresentados pelos dois pareceristas anônimos da revista Dados, pelos participantes do Grupo Temático em Políticas Públicas no $4^{\circ}$ Encontro Nacional da Associação Brasileira de Ciência Política - ABCP (Rio de Janeiro, 21-24 de julho de 2004) e pelos membros da banca de doutorado, Adrian Lavalle, Celina Souza, Fernando Haddad, Gabriel Cohn (orientador), e Marco Aurélio Nogueira.
}

DADOS - Revista de Ciências Sociais, Rio de Janeiro, Vol. 48, nํ2, 2005, pp. 271 a . 
Institucionalismo podem ser encontradas na nova economia institucional (Williamson, 1973; North, 1981) e no behaviorismo. Todas as três abordagens têm sido aplicadas a estudos sobre políticas públicas, embora o institucionalismo de escolha racional seja a linha teórica predominante. Elinor Ostrom (1997), uma das institucionalistas mais influentes na área de políticas públicas, adota a perspectiva da escolha racional, enquanto outra institucionalista bastante destacada na área, Theda Skocpol (1992; 1995), adota a perspectiva do institucionalismo histórico.

Como reveremos adiante, as três linhas de argumentação do Novo Institucionalismo implicam dificuldades teóricas, em especial quando aplicadas à análise de políticas públicas. Nos argumentos que desenvolverei aqui, busco demonstrar como a teoria de democracia de Habermas pode fornecer uma saída teórica para essas dificuldades. Para realizar essa tarefa, apresento, inicialmente, as linhas gerais do argumento habermasiano.

\section{A ABORDAGEM HABERMASIANA}

Em sua teoria social crítica, Habermas $(1984 ; 1987)$ sustenta que existiriam dois modos possíveis de ação social: a estratégica e a comunicativa. A ação estratégica corresponde ao modelo descrito por Weber para a ação cuja racionalidade é voltada para fins (Zeweckrationalität) na qual o ator busca realizar seus objetivos e, para isso, leva em consideração a ação dos demais indivíduos; Habermas (1987) refere-se à ela como a ação orientada para o "sucesso". A ação comunicativa, por outro lado, está orientada para o entendimento mútuo, ou seja, os atores sociais buscam harmonizar suas ações por meio de discursos que consistem na apresentação, crítica e obtenção de consenso sobre reivindicações de validade. Não é possível a profundar aqui os argumentos que Habermas apresenta para justificar a origem e o desenvolvimento desses dois tipos de ação social ${ }^{1}$. Basta ressaltar que cada uma dessas modalidades de ação está relacionada com uma orientação epistemológica específica. Na ação estratégica, trata-se de uma relação "sujeito-objeto", isto é, para o ator social, todos os elementos da sociedade, inclusive outros sujeitos, são tomados como objetos e utilizados como meios para alcançar o fim almejado. No caso da ação comunicativa, trata-se de uma relação "sujeito-sujeito", pois o ator considera os demais indivíduos com quem interage como sujeitos que também possuem a capacidade para o discurso e o entendimento. Cabe lembrar que, para 
Habermas, o consenso é um pressuposto sustentado por atores que buscam o entendimento. Portanto, não é necessário que corresponda à realidade empírica, mas apenas que sujeitos em interação considerem o consenso possível, desde que "a argumentação pudesse ser conduzida de maneira suficientemente aberta e se pudesse durar o tempo suficiente" (Habermas, 1984:42).

A teoria habermasiana do direito e da democracia, por sua vez, é desenvolvida a partir da tensão entre a facticidade e a validade das leis (Habermas, 1998). A facticidade refere-se ao caráter coercivo da lei positiva, e a validade, à legitimidade discursiva que cidadãos atribuem às leis. A eficácia das leis depende de ambos os aspectos, pois, em uma sociedade complexa, a validade não é suficiente para garanti-las, uma vez que indivíduos podem optar por agir estrategicamente sem consideração ao interesse geral, sendo necessário aplicar sanções para dissuadir comportamentos transgressores. Por outro lado, em uma democracia, apenas leis legítimas, isto é, aquelas que foram validadas discursivamente, podem aplicar sanções. Habermas argumenta que essa dupla necessidade já estava presente na idéia kantiana de um sistema legal como o protetor de liberdades individuais. De acordo com essa concepção, uma vez que o direito à liberdade pertence a todos, estes têm interesse de que as leis atuem no sentido de garantir esse direito, mesmo que seja necessário recorrer à coerção. Assim, as leis legítimas contam com o consentimento moral daqueles a quem são aplicadas. Habermas observa que, do ponto de vista da teoria da ação, isso quer dizer que indivíduos têm o direito de escolher qual orientação adotar: uma ação orientada para o sucesso ou para o entendimento mútuo.

"Para um ator que age [de acordo com os princípios] da escolha racional que tem a expectativa de que normas serão implementadas, os preceitos legais formam uma barreira de facto, com conseqüências calculáveis em caso de violação. Por outro lado, para um ator que deseja chegar a um entendimento com outros indivíduos sobre as condições [que podem garantir] o sucesso da ação de cada um, a reivindicação de validade da norma, bem como com a possibilidade de se reexaminar criticamente essa reivindicação, restringe a 'vontade individual' [Willen] do ator". (idem:30-31)

Essa opção aberta aos atores sociais não significa que exista uma fusão entre as duas modalidades de ação, observa Habermas. A opção por um tipo de ação, em dado momento, elimina a possibilidade da ação alternativa. Por outro lado, uma lei válida implica a idéia de que os dois 
aspectos estão sendo considerados simultaneamente. Desse modo, Habermas busca conciliar o modelo liberal, em que o Estado é o garantidor das liberdades individuais, com o modelo republicano, no qual a comunidade política é considerada a fonte da legitimidade. O modelo procedimental de democracia apresentado por ele considera que as duas orientações seriam necessárias nas sociedades complexas. Em síntese, as leis precisam de procedimentos democráticos que as tornem legítimas, e a eficácia das leis depende não apenas de sua legitimidade, mas também da aplicação de sanções.

\section{OS DILEMAS DO NOVO INSTITUCIONALISMO}

Vejamos agora como o argumento de Habermas pode ser aplicado à crítica do Novo Institucionalismo e de seu uso nos estudos de políticas públicas. Em geral, as investigações institucionalistas adotam uma orientação positivista, uma vez que procuram descrever e explicar a gênese de políticas públicas sem, no entanto, sugerir procedimentos visando a superar os efeitos negativos decorrentes do arranjo institucional estudado. $\mathrm{O}$ caráter positivo do institucionalismo, porém, parece sugerir que essa abordagem não tem nenhuma implicação normativa. Como explicar, então, o grande interesse que despertou entre os estudiosos de políticas públicas? Afinal, uma das finalidades da análise de políticas públicas é o desenvolvimento de instrumentos que possam aperfeiçoá-las. No entender de uma das mais conhecidas institucionalistas históricas, Ellen M. Immergut (1998), o problema do Novo Institucionalismo seria justamente o de não permitir uma orientação normativa. Ao comentar uma das questões mais importantes dessa linha teórica, ou seja, as assimetrias de poder geradas como efeitos secundários pelas instituições, a autora afirma que cabe aos institucionalistas sugerir maneiras para que as instituições forneçam resultados justos. No entanto, segundo sua avaliação, isso seria muito difícil de se obter devido aos próprios pressupostos do Novo Institucionalismo.

Immergut observa que essa abordagem surgiu como uma crítica ao behaviorismo, que aceita a idéia de que a soma das preferências individuais explica o comportamento coletivo. Contra essa concepção, os institucionalistas afirmam que a ação social é determinada por instituições, e não meramente pelo somatório das preferências. Mas, por outro lado, os institucionalistas também rejeitam o estruturalismo, o qual 
atribui a uma determinada estrutura social a força causal de todas as situações sociais. Segundo ela,

"Os institucionalistas criticam os behavioristas por aceitarem a expressão de preferências e a agregação de interesses na política por seu 'valor de face'. Mas eles não estão dispostos a adotar os padrões objetivos dos deterministas sociais e marxistas - ou, aliás, qualquer outro princípio $a$ priori-como a base para criticar ou melhorar arranjos políticos e sociais atuais. Em vez disso, eles tentam obter a 'quadratura do círculo' entre um padrão a priori e a posteriori recomendando procedimentos formais que podem ser usados para definir uma justiça substantiva. [...] A análise de procedimentos existentes e suas distorções fornece roteiros para essas recomendações institucionais. Mas o institucionalismo não pode fornecer uma teoria positiva de padrões que possa ser usada para avaliar escolhas políticas e seus resultados". (idem:11)

Na sua crítica do institucionalismo de escolha racional, Immergut confronta-se com o mesmo problema presente na teoria da escolha públi$\mathrm{ca}^{2}$. O pressuposto da maximização da utilidade teria levado institucionalistas da rational choice de volta à antiga abordagem behaviorista, alvo central das críticas do Novo Institucionalismo. Se as regras eleitorais ou de votações no Congresso influenciam as preferências de eleitores e legisladores, então não há como aceitar o argumento de que o resultado dessas regras expressa um padrão substantivo de justiça. Segundo os próprios institucionalistas, as instituições "camuflam" as verdadeiras preferências e distribuem o poder assimetricamente. Assim, a idéia de democracia como sendo um conjunto de regras que incluem votações e oportunidades de veto, formando assim instituições que representam um "Equilíbrio de Nash" ${ }^{3}$, não consegue superar o "Teorema da Possibilidade Geral" de Arrow, ou seja, a inviabilidade de uma função-utilidade social, uma vez que não é possível ordenar as preferências de indivíduos de forma a atender o interesse de todos os cidadãos (Arrow, 1963). "Embora extremamente consistente, [...] a conclusão de que a vontade popular é inconcebível significa na prática abandonar a busca por padrões substantivos e adotar uma atitude política não-intervencionista" (Immergut, 1998:14).

Segundo Immergut, a abordagem institucionalista da teoria das organizações também teria negligenciado as implicações normativas dos problemas observados no processo de tomada de decisões, ou seja, a assimetria de poder. Além disso, essa abordagem, que se apoiou inicialmente na concepção da racionalidade limitada, tornou-se cada vez 
mais radical. A teoria da "lata de lixo", por exemplo, sustenta que tanto a seleção de problemas como a aplicação de soluções aos mesmos são processos quase arbitrários, não havendo uma correspondência entre o problema a ser enfrentado e sua solução, mas sim uma adaptação do primeiro ao segundo (Cohen, March e Olsen apud Parsons, 1996). Immergut sustenta que mesmo a crítica a processos de dominação exercidos pelas organizações, adotada por alguns autores do institucionalismo organizacional, não poderia assumir uma postura normativa, pois não há um padrão de justiça a partir do qual a dominação pudesse ser aferida.

No entanto, o principal problema apontado pela autora na abordagem institucionalista - a falta de um padrão de justiça que possa ser utilizado no aperfeiçoamento das instituições - pode ser superado a partir dos argumentos habermasianos. Segundo a teoria de democracia de Habermas, não é necessário encontrar-se um padrão de justiça substantiva para criticar as limitações das instituições e recomendar alternativas. Qualquer instituição pode ser objeto de crítica e reforma; para isso, basta que a comunidade política chegue a um consenso - ou, mais provavelmente, a uma barganha justa, como observa Habermas em Between Facts and Norms (1998) - sobre as mudanças que devem ser introduzidas nas instituições existentes ou ainda sobre a criação de novas instituições. Em outras palavras, o padrão de justiça não é "externo" aos atores sociais, mas é construído por esses mesmos atores por meio de discursos práticos ${ }^{4}$. Assim, não é necessário recorrer a um padrão absoluto, sendo preciso apenas que os atores sociais busquem o entendimento mútuo sobre as reformas institucionais.

Habermas nos diz que esse é um processo contínuo, por meio do qual instituições são submetidas à constante revisão e reformulação. Não é possível - nem desejável - determinar uma instituição ideal a priori. Basta apenas que sejam adotados alguns critérios no processo deliberativo, como o "princípio de democracia". Para ele, a justiça não possui um conteúdo substantivo, pois depende de processos de validação de normas morais por intermédio dos discursos práticos que atendam ao "princípio de universalização" 6 . Habermas concebe a lei positiva como um componente da justiça, mas a primeira não se confunde com a última, pois a validade da lei é, na melhor das hipóteses, provisória, sendo passível de revisão diante de novas circunstâncias. Sendo um processo, a justiça não pode ser "positiva" como as leis, que representam apenas momentos de justiça "congelados" no tempo. 
Immergut, entretanto, não compreende a justiça como um processo dinâmico, sob constante revisão e mudança. Ela insiste que o Novo Institucionalismo deveria ser capaz de contribuir para a correção das assimetrias de poder induzidas por arranjos institucionais, mas isso exigiria uma teoria capaz de avaliar as relações de poder de uma forma objetiva:

\begin{abstract}
"A realização desse objetivo [,isto é, uma análise objetiva do poder], entretanto, exigiria uma segunda 'quadratura do círculo'. Não está absolutamente claro como se pode desenvolver um conceito não-determinista de poder. Mas eu acredito que isso valeria o esforço. [...] Alguma capacidade para acessar o poder potencial dos atores, independentemente das posições estratégicas nas quais se encontram (como no jogo da escolha racional) ou das suas percepções e comunicação simbólica (como na análise puramente interpretativa), poderia, a meu ver, ser útil". (Immergut, 1998:28)
\end{abstract}

Habermas, muito provavelmente, diria que esse objetivo é impossível, pois ninguém pode se colocar em uma situação transcendental em relação ao mundo-da-vida, de forma a aferir objetivamente qual seria a distribuição justa de poder. Além disso, a legitimidade de facto das instituições não pode ser estabelecida em termos teóricos, mas apenas pela prática, ou seja, pela deliberação intersubjetiva de atores sociais cujos projetos de vida são afetados pelas instituições. Qualquer padrão substantivo de justiça que possa ser utilizado na construção de instituições sociais não poderia ir além de uma solução tecnocrática.

E qual seria a posição do institucionalismo histórico em relação ao problema da assimetria de poder? Immergut - assim como Hall e Taylor (1996) - considera que o institucionalismo histórico se localiza em uma posição intermediária entre as outras duas abordagens, ou seja, essa perspectiva se localiza entre "a abordagem de escolha racional versus a da interpretação sociológica, ou a [abordagem] do 'cálculo' versus a da 'cultura'" (Immergut, 1998:28). Segundo a autora, os estudos desenvolvidos por institucionalistas históricos costumam se alinhar a uma ou outra corrente. Immergut considera que a questão da análise do poder é necessária para reaproximar as duas tendências, sem a qual a bifurcação do institucionalismo histórico, já em andamento, tenderia a se consolidar. Hall e Taylor, por sua vez, afirmam que não pretendem propor uma síntese entre as três perspectivas institucionalistas, mas que seria recomendável um intercâmbio entre as mesmas, uma vez que se desenvolveram de maneira independente umas das outras. Nesse 
caso, cabe perguntar: como essa "bifurcação" poderia ser reconciliada a partir da teoria de democracia de Habermas?

\section{UMA ALTERNATIVA HABERMASIANA}

O institucionalismo de escolha racional tem como pressupostos as preferências fixas e a maximização da função-utilidade pelos atores sociais. São, portanto, os mesmos pressupostos da teoria da escolha pública. Há, porém, uma diferença fundamental entre os institucionalistas do rational choice e os teóricos da public choice. Para os teóricos da escolha pública, a intervenção do Estado não pode corrigir as externalidades negativas geradas pelas ações de atores na sociedade sem causar outras externalidades igualmente indesejáveis, como a apropriação de bens públicos por políticos e burocratas além da "quota" individual (Buchanan, 1972). Por sua vez, os teóricos institucionalistas que se vinculam à abordagem da escolha racional crêem que as instituições são capazes de alterar as expectativas de atores que agem estrategicamente, o que pode assegurar efeitos sociais desejáveis. Como notam Hall e Taylor:

\footnotetext{
"As instituições estruturam tais interações, influenciando a abrangência e seqüência das alternativas na agenda de escolhas ou fornecendo informações e mecanismos de fiscalização que reduzam a incerteza sobre o comportamento correspondente dos outros e permitindo 'ganhos na troca', e assim levando os atores na direção de cálculos específicos e a resultados sociais potencialmente melhores". (1996:945)
}

Habermas (1998) também incorpora essa idéia da intervenção de instituições, pois a considera fundamental às democracias modernas, seja pela necessidade de legitimar normas sociais ou de impor sanções quando essas são violadas. As sanções aplicadas por instituições têm o objetivo de alterar o comportamento de atores que agem estrategicamente de modo que a vontade coletiva expressa nas leis possa ser preservada. Mas, para que essa sanção possa ser legitimamente aplicada, é preciso institucionalizar os procedimentos por meio dos quais as normas são estabelecidas. O institucionalismo de escolha racional é, nesse aspecto, perfeitamente compatível com a abordagem habermasiana. Habermas, porém, diferentemente dos institucionalistas de escolha racional, não considera que a ação estratégica é o único tipo de ação social possível, pois é preciso considerar também a ação comunicativa. No que se refere às instituições em uma democracia, Habermas considera 
que há uma dependência entre a ação estratégica e a ação comunicativa. A primeira só pode ser aceita como legítima enquanto não violar as normas que incorporam a razão comunicativa. Portanto, o institucionalismo de escolha racional falha ao não considerar a necessidade de legitimação comunicativa das instituições.

Em contraposição, o institucionalismo sociológico traz à tona a questão da legitimidade, pois, para os autores que adotam essa linha teórica, a própria emergência de instituições é considerada um processo de legitimação. A proximidade de elementos dessa abordagem com o conceito de mundo-da-vida da fenomenologia e a orientação epistemológica da sociologia interpretativa é clara, uma vez que o institucionalismo sociológico, como apontam Hall e Taylor,

“[...] enfatiza a maneira pela qual as instituições influenciam o comportamento fornecendo scripts cognitivos, categorias e modelos que são indispensáveis para a ação, principalmente porque sem eles o mundo e o comportamento dos outros não poderiam ser interpretados. [...] Em muitos casos, as instituições estariam fornecendo os próprios termos por meio dos quais o sentido é atribuído à vida social. Isso significa que instituições não afetam apenas o cálculo estratégico de indivíduos, como os institucionalistas de escolha racional afirmam, mas também influenciam suas preferências mais básicas e mesmo a própria identidade. As auto-imagens e identidades de atores sociais seriam constituídas de formas institucionais, imagens e sinais fornecidos pela vida social". (1996:949)

Os autores observam que, na visão dos institucionalistas sociológicos, a relação dos atores sociais com a sociedade não é apenas instrumental, mas também interpretativa. Em outras palavras, ainda que os institucionalistas sociológicos reconheçam a existência da ação estratégica, esta é complementada pela ação orientada para o entendimento mútuo. De maneira análoga, Habermas (1998) sustenta que apenas a orientação para o entendimento mútuo pode fornecer a legitimidade demandada pelas instituições formais que impõem sanções.

Como vimos acima, as duas abordagens básicas do Novo Institucionalismo correspondem à da escolha racional e a sociológica, enquanto o institucionalismo histórico ora inclina-se para uma ou para outra, "equilibrando-se no muro entre as outras duas abordagens" (Immergut, 1998:28). Também observamos que a abordagem da escolha racional assume os mesmos pressupostos da teoria da escolha pública, uma 
vez que se limita a um conceito de ação voltada para a realização de determinados fins, na qual atores se relacionam com os demais sujeitos como se fossem "objetos" a serem utilizados como meios. Diferentemente dos teóricos da escolha pública, porém, os institucionalistas da escolha racional consideram que as instituições podem aprimorar o contexto social. Na abordagem do institucionalismo de escolha racional, a explicação para a origem de instituições está limitada, basicamente, aos ganhos aferidos pela cooperação. Entretanto, a cooperação em si mesma não pode ser explicada a partir dos pressupostos da escolha racional, em especial quando assume orientação epistemológica do individualismo metodológico. Por outro lado, o institucionalismo sociológico reconhece a base comunicativa na formação de instituições, posto que, segundo essa abordagem,

"[...] práticas institucionais compartilhadas emergiriam de um processo interativo de discussão entre atores de uma dada rede [network] pertinente a problemas comuns, como os interpretar e como os solucionar - tendo lugar em uma variedade de fóruns que variam de escolas de administração a conferências internacionais. Como resultado de tais interações, os atores desenvolveriam mapas cognitivos em comum, geralmente incorporando uma noção de práticas institucionais apropriadas, que são então amplamente disseminadas". (Hall e Taylor, 1996:950)

Portanto, o pressuposto do individualismo metodológico é pertinente apenas à perspectiva rational choice do Novo Institucionalismo. O institucionalismo de escolha racional e o sociológico, ainda que considerados compatíveis com os pressupostos gerais do institucionalismo, acabam se colocando em campos teóricos opostos. Nota-se a falta de um argumento teórico capaz de estabelecer uma conexão entre a perspectiva do participante e a do observador. A resposta de Habermas (1987) para essa questão está em reaproximar duas concepções de sociedade que tomaram rumos independentes nas ciências sociais: a sociedade como mundo-da-vida e como sistema. Em seus argumentos, o processo de evolução social deve ser compreendido tanto como um aumento crescente da complexidade sistêmica quanto como um processo de racionalização do mundo-da-vida. Interpretações, normas de interação social e mesmo a identidade individual tornam-se cada vez mais dependentes da razão comunicativa, dado que orientações míticas e religiosas não são mais suficientes quando se estabelece a visão descentrada do mundo. Concomitantemente, a complexidade social não permite 
mais que a integração social seja "resolvida" apenas por meio da ação comunicativa, sendo necessários processos de integração sistêmica para estabilizar a ação estratégica de indivíduos, a qual surgiu com a diferenciação dos subsistemas da economia e da administração. Essa concepção permite compreender a sociedade como um "[...] sistema que tem que atender às condições para a manutenção de mundos-da-vida socioculturais" ou como "[...] complexos de ação sistemicamente estabilizados de grupos socialmente integrados" (idem:151-152, ênfases no original).

O Novo Institucionalismo, porém, não possui um referencial teórico que permita uma integração entre os conceitos de sistema e mundo-da-vida, limitando-se a tomar emprestados conceitos ora da teoria de escolha racional, ora da sociologia interpretativa. Se as abordagens básicas do Novo Institucionalismo têm em comum a idéia de que instituições condicionam o comportamento de indivíduos, cada uma delas possuirá um conceito de instituição bastante distinto. Para o institucionalismo de escolha racional, a instituição possui um caráter externo, impondo sobre os atores sociais restrições ao comportamento a partir de fora, assim como se dá na perspectiva hobbesiana. O institucionalismo sociológico, por sua vez, concebe a instituição como sendo construída pela interação dos atores sociais que elaboram normas de conduta às quais se submetem por reconhecê-las como legítimas. Para o institucionalismo de escolha racional, as instituições são sistemas que têm a função de exercer a coerção, seja por meio de incentivos ou da imposição de sanções, enquanto, para o institucionalismo sociológico, essas são compreendidas como referenciais normativos legitimados pelos atores sociais.

Pode-se dizer que o Novo Institucionalismo apresenta um dilema conceitual: embora a idéia de instituição seja o que confere unidade a suas abordagens, os conceitos de instituição utilizados não podem se conectar um ao outro pela falta de uma teoria adequada. Daí o problema apontado por Immergut - a incapacidade do Novo Institucionalismo de incorporar uma dimensão normativa - não residir na falta de uma "teoria positiva do poder" ou na necessidade de uma definição de "justiça substantiva", como a autora argumenta. A tarefa está em reconciliar a perspectiva sistêmica com a interpretativa e enfrentar a questão das assimetrias de poder por meio dos processos de legitimação de instituições. 


\section{UMA CRÍTICA AO INSTITUCIONALISMO DE ESCOLHA RACIONAL}

Para demonstrar como a perspectiva teórica de Habermas pode ajudar o Novo Institucionalismo a resolver o dilema entre o caráter externo das instituições e sua legitimidade, utilizo os argumentos teóricos apresentados por Elinor Ostrom, uma autora institucionalista que adota a abordagem de escolha racional. Ostrom tornou-se referência nos estudos de políticas públicas a partir da publicação, em 1990, de Governing the Commons: The Evolution of Institutions for Collective Action (1997). Diferentemente de Immergut, Ostrom, aparentemente, não se sentiu desconfortável em fazer recomendações normativas no texto em questão. O ponto, portanto, é verificar como Ostrom, partindo da perspectiva da escolha racional, aborda a questão da legitimidade. Como veremos adiante, a autora chega à idéia de entendimento mútuo como a base da legitimidade, mas não consegue desenvolver o argumento completamente por falta de conceitos teóricos adequados.

O foco da análise de Ostrom em Governing the Commons é o problema da ação coletiva no uso de recursos naturais de acesso aberto, chamados de Common Pool Resources - CPRs. Seu objetivo é explicar a existência de instituições capazes de regular o uso das $C P R s$ de modo a serem sustentáveis ao longo do tempo. Seu ponto de partida é o conhecido artigo de Garrett Hardin, "The Tragedy of the Commons" (apud Ostrom, 1997), no qual o autor afirma que a racionalidade da ação de cada indivíduo no uso de recursos naturais compartilhados levaria necessariamente ao esgotamento dos mesmos. O argumento de Hardin pode ser sintetizado nos seguintes termos: fazendeiros que usam um mesmo pasto não têm incentivos para reduzir o número de animais nele colocados, pois cada um deseja maximizar o próprio lucro; uma ação isolada pela redução do número de animais corresponderia à maior perda individual, o que desencoraja sua adoção. Como conseqüência, os recursos naturais compartilhados esgotam-se, e todos os usuários são prejudicados.

Ostrom nota que a "tragédia dos comuns" de que fala Hardin corresponde ao modelo do "Dilema do Prisioneiro", um jogo no qual a cooperação poderia deixar todos em melhor situação, mas isso não ocorre devido à incerteza que cada jogador tem em relação ao comportamento do outro, produzindo um resultado coletivo inferior ao Ótimo de Pareto $^{7}$. Ela também aponta para a convergência do modelo de Hardin com o modelo da lógica da ação coletiva descrito por Mancur Olson, segun- 
do o qual a ação coletiva não seria possível exceto em pequenos grupos, só acontecendo por meio de coerção externa. Nesse ponto da argumentação, Ostrom faz uma observação:

“O que torna esses modelos tão interessantes e tão poderosos é que eles capturam aspectos importantes de muitos problemas que ocorrem em diversas situações em todas as partes do mundo. O que torna esses modelos tão perigosos - quando usados metaforicamente como um fundamento para políticas - é que as restrições, que são consideradas fixas para o propósito da análise, são também consideradas fixas em situações empíricas, a não ser quando uma autoridade externa as muda. [...] Uma vez que indivíduos são vistos como prisioneiros [, isto é, incapazes de interferir na situação em que se encontram], as prescrições de políticas vão responder a essa metáfora. Eu preferiria responder à questão sobre como aumentar as capacidades daqueles indivíduos para mudarem as regras restritivas do jogo de modo a conduzi-los a resultados outros além das tragédias sem remorso". (Ostrom, 1997:6-7, ênfases minhas)

O que Ostrom quer dizer ao usar os termos "metaforicamente" e "metáfora"? Parece-me que ela está a um passo de identificar nos modelos da escolha racional a reificação da realidade social induzida pelos pressupostos dessa vertente. A autora reconhece que os modelos de Hardin e Olson fixam variáveis, que são, desse modo, assumidas como "objetos" do contexto social. No entanto, como ela mesma nota, trata-se de aspectos da sociedade que são, afinal, construídos por atores sociais e que, por isso, podem, em princípio, ser alterados. Mesmo sem utilizar o conceito de reificação - possivelmente por desconhecê-lo Ostrom aproxima-se intuitivamente do mesmo, pois o termo "metáfora" expressa basicamente a mesma idéia da reificação: trata-se de uma abstração que pressupõe a existência de "objetos" no contexto social. No entanto, há uma diferença fundamental entre a metáfora e a reificação: enquanto a primeira corresponde a uma expressão fora de seu lugar semântico usual para melhor revelar uma situação social ou psicológica, a segunda segue na direção contrária, pois cria um "objeto" que oculta aquilo que é, na verdade, uma relação social.

Ainda que não tenha percebido o aspecto da reificação, Ostrom nota que os pressupostos de teorias têm conseqüências para as políticas públicas:

"Ao se referir a situações ambientais como 'tragédia dos comuns', 'problemas de ação coletiva', 'dilemas do prisioneiro', 'recursos de acesso 
aberto', ou mesmo 'recursos de propriedade comum', o observador freqüentemente deseja invocar uma imagem de indivíduos incapazes, enredados em um processo inexorável de destruição de seus próprios recursos". (idem:8)

Segundo Ostrom, a partir dessa concepção sobre o comportamento de indivíduos, duas prescrições de políticas são usualmente apresentadas. A primeira corresponde ao modelo do Leviatã: a coerção externa exercida por instituições governamentais; a segunda, a privatização. Ela considera que essas recomendações são contraditórias e mutuamente excludentes: "Se uma recomendação está correta, a outra não pode estar" (idem:14). A bem da verdade, porém, as duas recomendações são perfeitamente consistentes com o pressuposto de agentes racionais e egoístas: como agentes privados, tenderão a proteger seu patrimônio e evitarão as sanções impostas pelo Estado. Coerentemente, o "Teorema da Possibilidade Geral" de K. Arrow não diz que os governos não podem impor sua vontade sobre indivíduos, mas que soluções coletivas satisfatórias só podem ser "impostas ou ditatoriais" (Arrow, 1963). Como Arrow deixou claro, a conseqüência de seu teorema é que "a doutrina da soberania dos eleitores é incompatível com a racionalidade coletiva" (idem:60). Buchanan também estava perfeitamente consciente da alternativa da coerção externa ${ }^{8}$; ele apenas condenava a ação do Estado em geral devido à suposta maximização da função-utilidade de políticos e burocratas, lógica que levou às prescrições do "Estado mínimo", inclusive por meio da privatização. Entretanto, Ostrom não percebe que a verdadeira inconsistência dos modelos da rational choice reside no pressuposto da razão instrumental como única forma possível de racionalidade.

Diferentemente dos teóricos da escolha pública, que se dedicaram ao desenvolvimento de modelos formais abstratos na sua elaboração teórica, Ostrom baseou-se em uma extensiva análise de situações empíricas de CPRs. Sua conclusão foi a de que indivíduos têm sim, afinal das contas, a capacidade de se organizarem para implementar objetivos comuns. Ela atesta que, para compreender essa constatação empírica, seria necessário desenvolver uma nova teoria da ação coletiva:

“O que está faltando na caixa de ferramentas do policy-analyst - e do conjunto de teorias da organização humana aceitas [e] bem-desenvolvidas - é uma teoria adequadamente específica da ação coletiva na qual um grupo de "principais' ${ }^{9}$ possa se organizar volunta- 
riamente e reter os resíduos de seus próprios esforços". (Ostrom, 1997:24-25)

Ostrom, no entanto, não se propõe a desenvolver tal teoria abrangente, mas sugere um quadro referencial (framework), envolvendo "fatores internos e externos que podem impedir ou aumentar a capacidade de indivíduos de usar e governar as CPRs" (idem:27). No entanto, ao mesmo tempo em que busca justificativas para demonstrar que os usuários de $C P R$ s são capazes de coordenar suas ações, seu quadro referencial não possui um conceito de ação social compatível com o objetivo a que a autora se propõe, ainda que se aproxime de uma concepção similar à ação comunicativa. Em dado momento, ela nos diz que adota "[...] um conceito amplo de ação racional, em lugar de uma concepção restrita" (idem:37). Esse conceito ampliado de racionalidade é concebido em termos de uma "estratégia contingente," segundo a qual indivíduos fazem escolhas racionais dentro de normas de interação social, como a regra de reciprocidade ( $t$ it-for-tat).

Ostrom concebe essas normas sociais como uma das quatro variáveis internas que afetam a escolha individual; as outras variáveis internas seriam: benefícios esperados, custos esperados e taxas de desconto. $\mathrm{O}$ primeiro aspecto a chamar atenção aqui é o fato de Ostrom colocar normas sociais lado a lado a variáveis típicas da análise econômica. Assim, apesar de reconhecer a importância das normas de interação social, para a coordenação da ação coletiva, a autora não coloca a elaboração dessas normas no centro de seu argumento. Sua abordagem, ainda dependente de conceitos e referências teóricas da rational choice, não consegue fazer a distinção entre o momento no qual atores sociais se orientam pela ação estratégica (avaliação de custos-benefícios e cálculos de taxas de desconto) e o momento no qual eles se referem ao mundo social, orientando-se pela ação comunicativa (normas consensuais de interação social). Ao longo do livro, ela não chega a especificar como normas sociais poderiam ser "capturadas" em termos de variáveis; pressupõe apenas que um mesmo quadro referencial pode abrigar variáveis que possuem dimensões de avaliação totalmente diversas entre si. Enquanto variáveis como custos, benefícios e taxas de desconto são expressas em termos quantitativos e verificadas segundo a perspectiva sujeito-objeto, normas de interação social pertencem à dimensão interpretativa e, portanto, só podem ser avaliadas em termos qualitativos e de acordo com a perspectiva sujeito-sujeito. Como observou Habermas (1984), a quantificação de interações sociais é um risco quando se 
ignora sua base interpretativa, pois isso, em última instância, leva à reificação. Desse modo, o quadro referencial de Elinor Ostrom, ainda que incorpore normas de interação social como elementos importantes, faz essa incorporação sem qualquer menção às diferentes orientações epitemológicas que estão subjacentes à questão.

Cabe ainda perguntar: o que seria mais relevante para a formulação de políticas públicas? Calcular o comportamento de atores sociais, elaborando-se modelos nos quais normas são classificadas (p. ex., regras de reciprocidade, respeito mútuo, solidariedade etc.) e então quantificadas (regra presente/ausente; intensidade alta/baixa etc.)? Ou simplesmente incorporar o princípio do entendimento mútuo aos inumeráveis contextos aos quais as políticas públicas se aplicam? Ostrom acaba cedendo à tentação de recomendar a estratégia do "cálculo do comportamento", deixando de lado a adoção de conceitos mais amplos, capazes de explicar o fenômeno da cooperação.

Na mesma época em que a autora procurava decifrar em termos de variáveis o processo cooperativo observado nas CPRs, a obra de Habermas já era debatida nos meios acadêmicos americanos. Entretanto, pelo que podemos concluir da leitura de seus trabalhos, Ostrom desconhecia esse debate. E seria justamente essa discussão que poderia levar a autora a encontrar uma saída para os impasses teóricos apresentados pela cooperação nas CPRs. Sem uma teoria capaz de fundamentar o entendimento mútuo, seu quadro referencial ficou limitado a uma proposta sobre a relevância de algumas variáveis na elaboração de regras para o uso das CPRs, como se pode constatar na Figura 1. Ostrom faz questão de ressaltar que cada $C P R$ s corresponde a uma situação bastante específica; por isso seria quase impossível elaborar teorias e modelos generalizáveis para todos os casos. Segundo ela,

"Este quadro de referências, [criado] para analisar o problema da escolha institucional, ilustra as configurações complexas de variáveis que devem ser consideradas quando indivíduos em condições de campo tentam elaborar regras para melhorar seus resultados individuais e coletivos. A razão para apresentar esse conjunto complexo de variáveis como um quadro referencial e não como um modelo se deve ao fato de que não se pode abranger (pelo menos não com os métodos atuais) esse grau de complexidade em um único modelo. Quando se escolhe modelar relações [entre variáveis], pode-se incluir apenas um subconjunto de variáveis, e mesmo assim é geralmente necessário fixar algumas dessas ao valor zero ou a um valor absoluto. Os pressupostos típicos de 
Figura1

Variáveis Afetando a Escolha Institucional

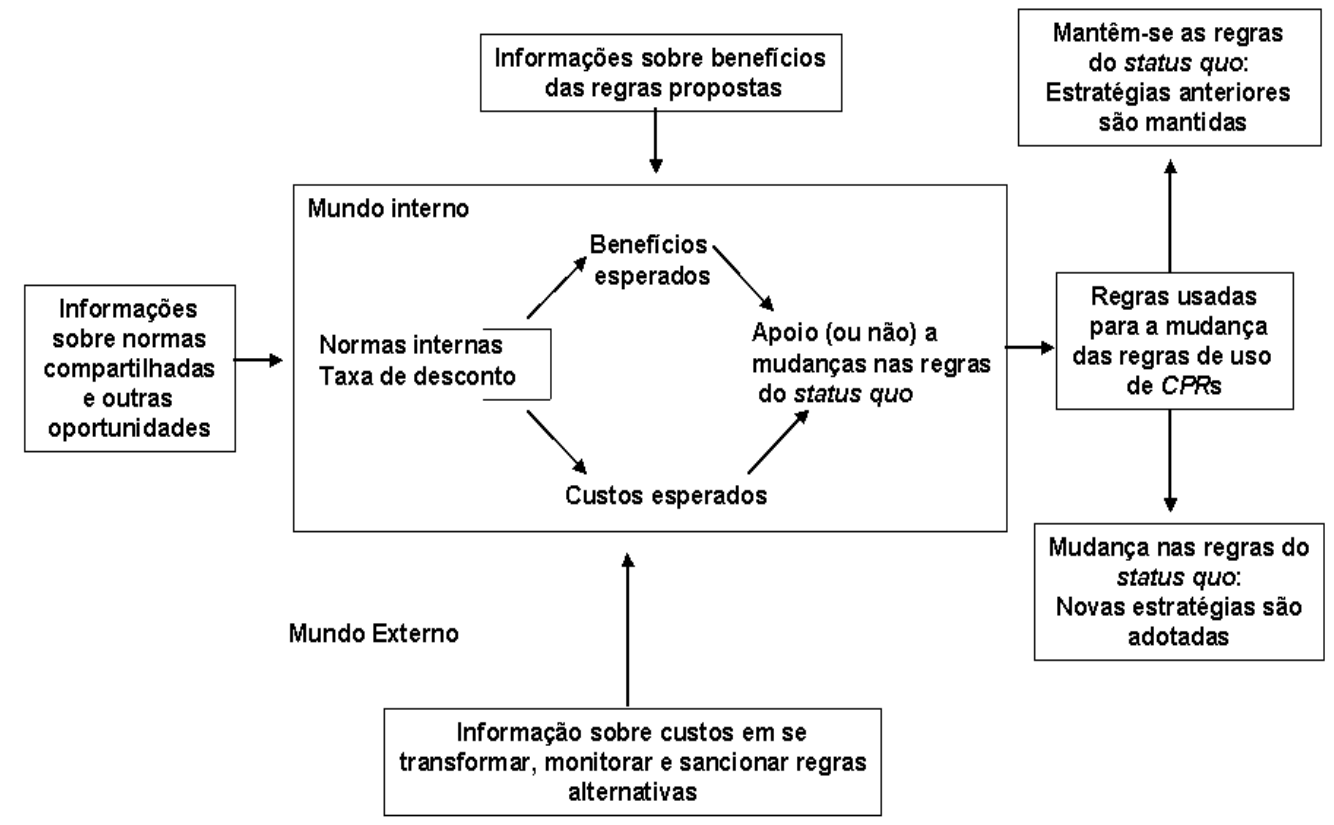

Fonte: E. Ostrom, 1997, p.193.

informações completas, ação independente, simetria perfeita de interesses, ausência de erro humano, ausência de normas de reciprocidade, nenhum custo de monitoramento e na aplicação de sanções, e nenhuma capacidade para transformar a própria situação levam a modelos altamente específicos, não a teorias universalizáveis. É tão necessário mapear o terreno para um conjunto de modelos quanto desenvolver modelos específicos. Para que as ciências sociais se tornem relevantes para a análise de problemas de políticas públicas, o desafio deverá ser o de integrar esforços para mapear o amplo terreno, assim como esforços para desenvolver modelos compatíveis com nichos específicos nesse terreno". (Ostrom, 1997:215)

Se o policy-maker compreendesse o papel do entendimento mútuo na coordenação de atores sociais, a especificidade de modelos deixaria de ser um problema, pois o que passaria a ter importância seria a compreensão do princípio que norteia as ações sociais cooperativas, e não um modelo capaz de prever a ação coletiva. A recomendação de Habermas no que se refere às políticas públicas é suficientemente abrangente para incluir todas as situações em que a integração social é fundamental para a reprodução dos componentes estruturais do mundo-da-vida; para ele, nas sociedades de Estado de Bem-Estar Social, é preciso proteger a ação comunicativa das intervenções sistêmicas, especialmente em setores de políticas públicas como educação e assis- 
tência social (Habermas, 1984). Também é necessário legitimar as instituições que impõem sanções (Habermas, 1998). O contexto das CPRs pode ser compreendido, portanto, como uma situação na qual normas, para serem eficazes, demandam uma base de legitimidade mais direta do que as leis generalizáveis são capazes de oferecer. É justamente por isso que Habermas se refere ao problema da juridificação, pois leis abrangentes são incapazes de atender às especificidades dos contextos sociais. A relação entre a especificidade do contexto e a legitimidade representa um "ponto cego" na abordagem teórica de Ostrom. Ao longo da argumentação desenvolvida em Governing the Commons, a questão da legitimidade vem à tona em diversos momentos, mas permanece marginal ao argumento geral. Vejamos, por exemplo, a seguinte passagem:

"Quando modelos pressupõem nenhuma comunicação e nenhuma capacidade para mudar as regras aplicadas às $C P R$ s de pequena escala, eles são aplicados fora de sua abrangência. Aplicar modelos fora da abrangência pertinente pode produzir mais danos do que benefícios. Políticas públicas baseadas na noção de que todos os usuários de CPRs são incapazes e devem ter regras impostas sobre eles podem destruir o capital institucional que foi acumulado durante os anos de experiência em localidades específicas, como foi ilustrado pelos casos dos recursos pesqueiros da Nova Escócia". (Ostrom, 1997:184)

Em outras palavras, a legitimidade proporcionada pelo processo de entendimento mútuo seria muito mais eficaz do que a imposição de normas de "cima para baixo". Além de notar a importância da legitimidade comunicativa de normas para a sustentabilidade das CPRs, Ostrom também parece ter intuído a diferença entre ação comunicativa e ação estratégica:

"Dados referentes a benefícios, custos, normas compartilhadas e oportunidades são variáveis-síntese [summary variables] que afetam a decisão de um indivíduo em dar apoio ou não a uma mudança das regras do status quo. Se as três condições apresentadas a seguir forem contempladas, o analista institucional precisa apenas obter o valor das variáveis-síntese para prever estratégias individuais:

1.Existem medidas acuradas para cada uma das variáveis-síntese.

2.Indivíduos traduzem acurada e completamente informações sobre os benefícios líquidos e custos esperados.

3.Indivíduos comportam-se de uma maneira franca e não estratégica". (idem:194; ênfases minhas) 
Como podemos notar, o que seria o aspecto fundamental na teoria crítica de Habermas, ou seja, o pressuposto da sinceridade de atores que buscam o entendimento mútuo, na concepção de Ostrom, é uma das condições necessárias para "prever estratégias individuais". A autora chega a reconhecer que a sinceridade seria a condição fundamental para o sucesso na construção de regras de uso de CPRs:

\begin{abstract}
"A terceira condição é equivalente à afirmação de que indivíduos não se comportem de maneira oportunista para tentar obter benefícios maiores que aqueles obtidos por meio de um comportamento sincero. Essa condição implica que indivíduos revelam as suas avaliações honestamente, contribuem para os benefícios coletivos sempre que fórmulas para distribuição de custos estiverem presentes e estão dispostos a investir tempo e recursos para encontrar soluções para problemas compartilhados. Se essa condição fosse atendida, desapareceria parte do comportamento estratégico esperado em todos os dilemas sociais" (idem:195).
\end{abstract}

Portanto, Ostrom parece estar ciente da importância do entendimento mútuo como o princípio que sustenta os casos das CPRs bem-sucedidas. No entanto, seu quadro referencial negligencia esse aspecto e se mantém fiel aos pressupostos da perspectiva sujeito-objeto. Ostrom insiste em se manter dentro dessa perspectiva e até sugere as condições que seriam capazes de garantir a previsibilidade da ação social. Porém, deve-se notar que, além da sinceridade, as outras condições que a autora apresenta - "medidas acuradas" das variáveis-síntese e uma "tradução acurada e completa" de informações sobre custos e benefícios - não são atendidas em contextos reais, como $\mathrm{H}$. Simon (1997) nos ensinou com seu conceito de racionalidade limitada. Assim sendo, podemos concluir que não é possível prever as estratégias individuais de usuários de $C P R$ s. Do ponto de vista do cientista positivista, a falta de previsibilidade de uma teoria significa seu fracasso. Porém, se ampliarmos a perspectiva epistemológica, como faz Habermas, a dimensão prática volta a ter relevância teórica. Cabe lembrar que a dimensão prática não pode ser abordada com fins de previsão, pois a ação social pressupõe que atores têm capacidade de reflexão para mudar o contexto em que atuam (Habermas, 1973). Ostrom reconhece que os usuários de $C P R$ s podem mudar seus contextos de ação e inclui a hipótese de alteração nas regras de uso dos recursos das CPRs em seu quadro referencial, entretanto ainda considera ser necessário o desenvolvimento de modelos nomológicos. 
Cabe perguntar para quê esses modelos nomológicos seriam necessários, uma vez que a própria Ostrom reconhece que a especificidade dos contextos de CPRs implica uma diversidade de modelos que, no limite, tornaria tecnicamente inviável o desenvolvimento e aplicação dos mesmos a situações reais. Além disso, como Ostrom fez questão de afirmar, as CPRs que foram bem-sucedidas em estabelecer regras de uso chegaram a essa situação sem a intervenção de agentes governamentais. Como a autora observa, a interferência governamental na determinação das regras mostrou-se mesmo prejudicial para a sustentabilidade de CPRs. Quando muito, órgãos públicos contribuíram positivamente fornecendo informações sobre o meio físico das CPRs. Como explicar que pessoas comuns, sem nenhuma capacitação especial, chegaram a resultados tão positivos? Habermas diria que a explicação reside no fato de que os usuários de CPRs têm a única capacitação necessária para coordenar seus objetivos: a linguagem comum. Ostrom, porém, não reflete sobre as $C P R$ s segundo conceitos habermasianos, como sabemos. Limitada à perspectiva do institucionalismo de escolha racional, acaba dirigindo sua atenção e esforço de teorização para a identificação (e quantificação) de variáveis referentes ao contexto das CPRs, almejando a previsibilidade do comportamento dos atores sociais. Com isso, assimila o interesse subjacente às ciências empírico-analíticas, ou seja, "o controle técnico sobre processos objetificados" (Habermas, 1971:309). Ainda assim, sua perspicácia de observadora não deixa de notar que o entendimento mútuo está sempre presente nas CPRs sustentáveis.

Oito anos depois da publicação de Governing the Common, Ostrom continuava a procurar respostas para compreender os resultados da ação coletiva que observou nas suas investigações empíricas. Porém, seus conceitos ainda eram derivados do institucionalismo de escolha racional. Em artigo publicado em 1998, Ostrom reafirmou sua convicção de que a ação coletiva depende de normas de interação social. O tom do parágrafo de abertura é de quem sabe que está confrontando o mainstream da ciência política:

"Deixe-me começar com uma afirmação provocativa. Você não estaria lendo esse artigo se não fosse pelo fato de nossos ancestrais terem aprendido como empreender ações coletivas para solucionar dilemas sociais. Gerações sucessivas adicionaram ao estoque do conhecimento comum conhecimento sobre como desenvolver normas produtivas de comportamento em seus filhos e criar regras de apoio à ação coletiva 
que produzem bens coletivos e evitam a 'tragédia dos comuns'. O que nossos ancestrais e contemporâneos aprenderam sobre o engajamento em ações coletivas para defesa mútua, criação dos filhos e sobrevivência não é, entretanto, explicado pela atual teoria da ação coletiva". (1998:1)

Mais uma vez, Ostrom insiste na insuficiência da teoria da ação coletiva tal qual desenvolvida pela teoria da escolha racional. Como no seu trabalho anterior, ela não se arrisca a apresentar uma teoria da ação coletiva alternativa, sugerindo apenas um esquema representando cenários cooperativos que, como ela espera, possam servir para tal empreendimento. Dessa feita, porém, Ostrom é bem mais explícita sobre o papel da comunicação na solução de dilemas sociais.

Nesse artigo, em lugar de apresentar estudos de caso de CPRs, Ostrom discute uma abundante literatura sobre experimentos simulando dilemas sociais, com o objetivo de demonstrar que há muitas evidências de que indivíduos são capazes de resolvê-los. A autora constata que as previsões fornecidas pelos modelos tradicionais de escolha racional não explicam os resultados empíricos observados nesses experimentos e conclui ser necessário o desenvolvimento de uma segunda geração de modelos de racionalidade que inclua os "relacionamentos centrais" observados na solução dos dilemas sociais, a saber: "confiança," "reciprocidade" e "reputação". Ostrom agora deseja ir além de simplesmente considerar normas de interação social como variáveis-síntese. Com isso, a proxima-se ainda mais da idéia de ação comunicativa. Seu ponto de partida é a constatação de que o modelo de "racionalidade completa" - entendido como o modelo do Homo œconomicus - explica apenas uma parte do comportamento verificado em situações de dilemas sociais.

Para que a cooperação observada empiricamente possa ser explicada, seria necessário expandir a concepção de racionalidade. Curiosamente, Ostrom adota o termo "racionalidade limitada" para expressar esse outro tipo de racionalidade que estaria atuando nos processos cooperativos, observando que os "[...] modelos de racionalidade completa e limitada poderão se tornar mais complementares na próxima década do que é o caso hoje" (idem:16). Se substituíssemos a palavra "completa" por "estratégica" e "limitada" por "comunicativa," poderíamos, à luz da abordagem habermasiana, entender mais claramente quais são os tipos de racionalidade atuantes quando indivíduos decidem coope- 
rar uns com os outros e quando se envolvem em cálculos estratégicos. Ostrom, entretanto, não tem a seu alcance o conceito de racionalidade comunicativa capaz de fundamentar a cooperação na ação coletiva, mas, no entanto, não pode negar a existência de um outro tipo de racionalidade que viabiliza a cooperação.

Os relacionamentos centrais identificados por Ostrom - reputação, confiança e reciprocidade - podem ser interpretados segundo a abordagem do pragmatismo formal da teoria social de Habermas (1984). Uma reputação compatível com um processo de cooperação pressupõe que todos os participantes devem ser considerados iguais em suas capacidades de participação, sem que façam uso de relações de poder para impor seus interesses. O relacionamento "confiança" pode ser entendido como a dimensão "sinceridade," que é implícita ou explicitamente abordada na apresentação, discussão e deliberação de reivindicações de validade. A reciprocidade, por sua vez, é uma norma moral universal presente em praticamente todas as culturas conhecidas, o que justifica o reconhecimento do entendimento mútuo como fenômeno social universal. Segundo o esquema proposto por Ostrom (ver Figura 2), variáveis estruturais exógenas - grupo pequeno, simetria entre interesses e recursos (distribuição justa de recursos), baixo custo no provimento do bem público, horizonte de tempo amplo e "comunicação face-a-face" - afetam as variáveis estruturais endógenas (reputação, confiança e reciprocidade) e, em última instância, o nível de cooperação alcançado. Nesse esquema, embora a comunicação seja um elemento importante, seu papel fica ainda nivelado ao das demais variáveis estruturais exógenas, quando, se adotamos a perspectiva habermasiana, deveria constituir-se no aspecto central da cooperação na ação coletiva.

Concluindo, podemos notar que Ostrom não faz distinção entre "comportamento" e "ação", entre interações "sujeito-objeto" e "sujeito-sujeito," ou entre "individualismo metodológico" e "entendimento intersubjetivo". Se, por um lado, Ostrom avança ao introduzir em seu esquema as relações sociais, ou seja, os "relacionamentos centrais", de outro, seu arsenal de conceitos não é amplo o suficiente para fundamentar a cooperação. A autora parece mesmo relutar em abandonar o pressuposto do individualismo metodológico, como indica a seguinte passagem de seu artigo: "Confiança, reciprocidade e reputação podem ser incluídos em modelos formais de comportamento individual" (Ostrom, 1998:14). Ostrom, porém, não esclarece como interações so- 
Figura 2

Cenário Teórico Simples: Influência de Variáveis Exógenas sobre Variáveis Estruturais Endógenas (em negrito)



Fonte: E. Ostrom, 1998, p.15.

ciais poderiam ser reduzidas a comportamentos individuais e assim introduzidas em modelos formais. Tudo leva a crer que a ambição pelo desenvolvimento de modelos científicos tornou-se um fardo que impede Ostrom de adotar conceitos da sociologia interpretativa, o que permitiria uma explicação mais coerente para o fenômeno da cooperação. Apesar dos insights sobre o papel da comunicação da elaboração de normas de interação social, Ostrom insiste em buscar na epistemologia positivista as respostas para a sua teorização sobre a cooperação. Entretanto, desta vez sua ênfase não é nos estudos empíricos das CPRs, mas nos experimentos controlados. Mesmo considerando que os estudos de campo são importantes para o desenvolvimento teórico, Ostrom afirma que uma teoria de "segunda geração" da ação coletiva deveria se basear em experimentos laboratoriais:

"Enquanto alguns acadêmicos questionam o valor de experimentos de laboratório para testar previsões das principais teorias das ciências sociais, esse método tem muitas vantagens. Primeiro, pode-se planejar experimentos que testem múltiplas previsões para a mesma teoria sob condições controladas. Segundo, a replicação torna-se viável. Terceiro, pesquisadores podem questionar se determinado desenho [experimental] capta adequadamente as variáveis pertinentes à teoria e con- 
duzir experimentos adicionais para verificar como mudanças no arranjo experimental afetam os resultados". (idem:4)

Assim sendo, Ostrom acaba retornando para o campo do behavorismo, do qual o Novo Institucionalismo se separou como um movimento crítico. Naturalmente, a autora ainda está interessada em obter respostas sobre "como instituições aumentam ou restringem a construção da confiança mútua, reciprocidade e reputações” (idem:17). Mas sua insistência na construção de modelos capazes de prever o comportamento individual acaba impedindo a incorporação de perspectivas já adotadas pelos institucionalistas sociológicos.

Quanto à notória aversão dos teóricos da escolha racional a abordagens normativas nas ciências sociais - ainda que não tenham conseguido ser fiéis a esse intento -, Ostrom não deixa dúvidas sobre o que pensa disso:

“Enquanto muitos cientistas sociais alegam ter eliminado o ensino dos fundamentos normativos de uma comunidade política democrática, na verdade eles introduzem a norma do cinismo e da desconfiança sem fornecer uma visão de como cidadãos poderiam fazer algo para desafiar a corrupção, o rent-seeking ou políticas elaboradas de maneira negligente". (idem:3)

Entretanto, uma vez que Ostrom não consegue assimilar a idéia do entendimento mútuo, sua própria perspectiva normativa permanece restrita a uma postura cientificista, pois atribui aos modelos de "segunda-geração" de ação coletiva uma tarefa que só poderia ser levada adiante pela deliberação da comunidade política. Sua expectativa normativa para uma sociedade mais justa se volta para a "engenharia social", na qual a ciência tem primazia sobre a legitimidade. Para ela, cabe a uma nova teoria da ação coletiva estabelecer os parâmetros para a convivência social, uma vez que "[...] a educação cívica poderá ser baseada em teorias empiricamente válidas de ação coletiva, fortalecendo cidadãos que usam a 'ciência e arte da associação' (Tocqueville [1835 e 1840] 1945) para ajudar a sustentar comunidades políticas no século XXI" (idem:16). Podemos notar que Ostrom interpreta a palavra "ciência" literalmente, distorcendo o sentido que Tocqueville provavelmente atribuía à mesma, ou seja, a capacidade de organização como uma poderosa ferramenta dos cidadãos da então jovem nação americana. Assim, a pesar de ter apresentado uma importante contribuição para a crítica dos modelos de ação coletiva de escolha racional, Ostrom acaba 
perdendo a oportunidade de restaurar a dimensão prática perdida na teorização dos rational choicers. Sem isso, de nada adianta buscar instituições justas, pois a legitimidade não pode ser criada por instituições, mas sim pela sociedade, que é construída pela ação e reflexão humanas.

\section{CONSIDERAÇÕES FINAIS}

Não há dúvida de que existem muitos aspectos teóricos que têm implicação para a prática democrática da formulação e implementação de políticas públicas. Neste artigo, apresento uma discussão das implicações do Novo Institucionalismo, destacando a importância desta linha teórica nos estudos sobre políticas públicas. Como observação geral, pode-se dizer que, apesar de existirem três abordagens institucionalistas, o institucionalismo de escolha racional tem sido a abordagem mais influente, enquanto o institucionalismo sociológico tem sido pouco explorado nos estudos sobre políticas públicas. Isto talvez seja conseqüência dos rumos controversos que essa perspectiva tomou, como refletido na teoria da "lata de lixo" ${ }^{10}$. No entanto, o Novo Institucionalismo poderia ganhar uma dimensão mais equilibrada e realista, caso reintroduzisse a perspectiva da sociologia interpretativa em suas análises. Não se trata de descartar a abordagem de escolha racional, mas sim de reconhecer os limites de seu alcance teórico. Mais do que isso: trata-se de considerar as duas perspectivas simultaneamente. É nesse sentido que a contribuição da obra de Habermas se mostra relevante para a investigação de políticas públicas em contextos democráticos.

(Recebido para publicação em janeiro de 2005)

(Versão definitiva em abril de 2005) 


\section{NOTAS}

1. O argumento é desenvolvido em detalhes por Habermas nos dois volumes de The Theory of Communicative Action $(1984 ; 1987)$.

2. Para uma análise da teoria da escolha pública e suas implicações na reforma do Estado, ver Andrews (2004).

3. Na teoria dos jogos, o "Equilíbrio de Nash" representa a situação na qual nenhum dos atores envolvidos tem um incentivo para abandonar a situação em que se encontra (ver Ordeshook, 1995).

4. "Discurso prático" é o termo utilizado por Habermas para designar o processo comunicativo por meio do qual atores sociais buscam o entendimento mútuo sobre normas de interação social.

5. Esse princípio é definido da seguinte maneira: "[...] apenas aqueles estatutos que podem contar com o consentimento (Zustimmung) de todos os cidadãos em processos discursivos de legislação, processos esses que tenham sido, por sua vez, legalizados, podem ser considerados legítimos" (Habermas, 1998:110).

6. Habermas define o "princípio de universalização" como sendo a regra adotada em discursos práticos que buscam validar normas morais, nos quais "todos os afetados podem aceitar as conseqüências e efeitos secundários que a aceitação geral [da norma] é esperada de causar na satisfação dos interesses de todos (e essas conseqüências são preferíveis àquelas possíveis alternativas para a regulação)" (1990:65-66).

7. Uma breve descrição do famoso "Dilema do Prisioneiro" pode ser encontrada em Hollis (1994).

8. Como observou Udehn (1996), Buchanan foi um dos primeiros a analisar o problema dos bens públicos como sendo similar ao "Dilema do Prisioneiro". Para Buchanan, a provisão de bens públicos só poderia ser resolvida pela taxação coerciva. Entretanto, o problema da eficiência na alocação desses bens públicos não poderia ser solucionado. A saída, nesse caso, seria o estabelecimento de restrições constitucionais para a expansão do governo.

9. O termo "principais" refere-se ao modelo agent- principal (ver Przeworski, 1998).

10. Ver, entre outros críticos dessa abordagem, Bruun (1994) e Bendor, Moe e Shotts (2001). 


\section{REFERÊNCIAS BIBLIOGRÁFICAS}

ANDREWS, Christina. (2004), “A Teoria da Escolha Pública e as Reformas do Estado: Uma Crítica Habermasiana". Leviathan, no 1, pp. 73-98.

ARROW, Kenneth. (1963), Social Choice and Individual Values (2 ${ }^{\mathrm{a}}$ ed.). New Haven, Yale University Press.

BENDOR, Jonathan, MOE, Terry M. e SHOTTS, Kenneth W. (2001), “Recycling the Garbage Can: An Assessment of the Research Program". American Political Science Review, vol. 95, no 1, pp. 169-190.

BRUUN, Finn. (1994), “Hegelian Garbage Cans". Journal of Theoretical Politics, vol. 6, nำ1, pp. 119-127.

BUCHANAN, James M. (1972), "Politics, Policy, and the Pigovian Margin”, in J. M. Buchanan e R. Tollison (orgs.), The Theory of Public Choice. Ann Arbor, University of Michigan Press, pp. 169-182.

HABERMAS, Jürgen. (1971), "Knowledge and Human Interest: A General Perspective", in Knowledge and Human Interest (traduzido por J. J. Shapiro). Boston, Beacon Press, pp. 301-317.

. (1973), "The Classical Doctrine of Politics in Relation to Social Philosophy", in Theory and Practice. Boston, Beacon Press, pp. 41-81.

. (1984), The Theory of Communicative Action - Reason and Rationalization of Society (traduzido por Thomas McCarthy). Boston, Beacon Press, vol. 1.

. (1987), The Theory of Communicative Action: Lifeworld and System - A Critique of Functionalist Reason (traduzido por Thomas McCarthy). Boston, Beacon Press, vol. 2.

. (1990), Moral Consciousness and Communicative Action. Cambridge, MIT Press.

. (1998), Between Facts and Norms: Contributions to a Discourse Theory of Law and Democracy (traduzido por William Rehg). Cambridge, MIT Press.

HALL, Peter. A. e TAYLOR, Rosemary C. (1996), "Political Science and the Three New Institutionalisms". Political Studies, no XLIV, pp. 936-957.

HOLLIS, Martin. (1994), The Philosophy of Social Science: An Introduction. Cambridge, Cambridge University Press.

IMMERGUT, Ellen M. (1998), “The Theoretical Core of the New Institutionalism". Politics \& Society, vol. 26, no 1, pp. 5-34.

NORTH, Douglas. (1981), Structure and Change in Economic History. New York, Norton.

ORDESHOOK, Peter. (1995), Game Theory and Political Theory: An Introduction. New York, Cambridge, University Press.

OSTROM, Elinor. (1997) [1990], Governing the Commons: The Evolution of Institutions for Collective Action. Cambridge, Cambridge University Press.

. (1998), "A Behavioral Approach to the Rational Choice Theory of Collective Action". American Political Sciences Review, vol. 92, no 1, pp. 1-22.

PARSONS, Wayne. (1996), Public Policy: An Introduction to the Theory and Practice of Policy Analysis. Chektenham, Edward Elgar. 
PRZEWORSKI, Adam. (1998), "Sobre o Desenho do Estado: Uma Perspectiva Agent-Principal", in L. C. Bresser Pereira e P. Spink (orgs.), Reforma do Estado e Administração Pública Gerencial. Rio de Janeiro, Fundação Getulio Vargas Editora, pp. 39-73.

SIMON, Harold. (1997), Administrative Behavior: A Study of Decision-Making Processes in Administrative Organizations ( $4^{\mathrm{a}}$ ed.). New York, Free Press.

SKOCPOL, Theda. (1992), Protecting Soldiers and Mothers: The Origins of Social Policy in the United States. Cambridge, Belknap Press of Harvard University Press. . (1995), “Why I am an Historical Institutionalist". Polity, vol. 28, nº 1, pp. 103-106.

UDEHN, Lars. (1996), The Limits of Public Choice: A Sociological Critique of the Economic Theory of Politics. London, Routledge.

WILLIAMSON, Oliver E. (1973), "Markets and Hierarchies: Some Elementary Considerations". American Economic Review, vol. 63, no 2, pp. 316-325.

\section{ABSTRACT \\ Theoretical Implications of the New Institutionalism: A Habermasian Approach}

The current article analyzes the theoretical implications of the New Institutionalism, especially in public policy-making, adopting Jürgen Habermas' theories of action and democracy as the critical reference. Based on an analysis of texts by two leading institutionalists - Ellen Immergut and Elinor Ostrom -, the article argues that the New Institutionalism, especially the approach that adopts the premises of rational choice, meets its limits in a concept of action limited to strategic action and negligence vis-à-vis processes of institutional legitimization. It is suggested that the institutionalist approach can overcome its dilemmas by adopting a Habermasian perspective, since the latter integrates the concepts of strategic action and communicative action in the same theoretical argument and presents legitimacy as the central aspect in the concept of justice.

Key words: New Institutionalism; rational choice; collective action; public policies; legitimacy; critical theory 


\section{RÉSUMÉ}

Implications Théoriques du Nouvel Institutionnalisme: Une Approche Habermasienne

Dans cet article, on examine les implications théoriques du Nouvel Institutionnalisme, surtout dans l'élaboration des politiques publiques, en adoptant comme référence critique les théories de l'action et de la démocratie de Jürgen Habermas. À partir de l'analyse de textes de deux renommées institutionnalistes - Ellen Immergut et Elinor Ostrom - on avance que le Nouvel Institutionnalisme, surtout dans son approche comprenant les pressupposés du choix rationnel, trouve ses limites dans un concept d'action limité à l'action stratégique, et dans la négligence des processus de légitimation des institutions. On suggère que l'approche institutionnaliste peut dépasser ses dilemmes en adoptant la perspective habermasienne, puisque celle-ci réunit les concepts d'action stratégique et d'action communicative dans une même argumentation théorique et présente la légitimité comme l'aspect central de l'idée de justice.

Mots-clé: Nouvel Institutionnalisme; choix rationnel; action collective; politiques publiques; légitimité; théorie critique 